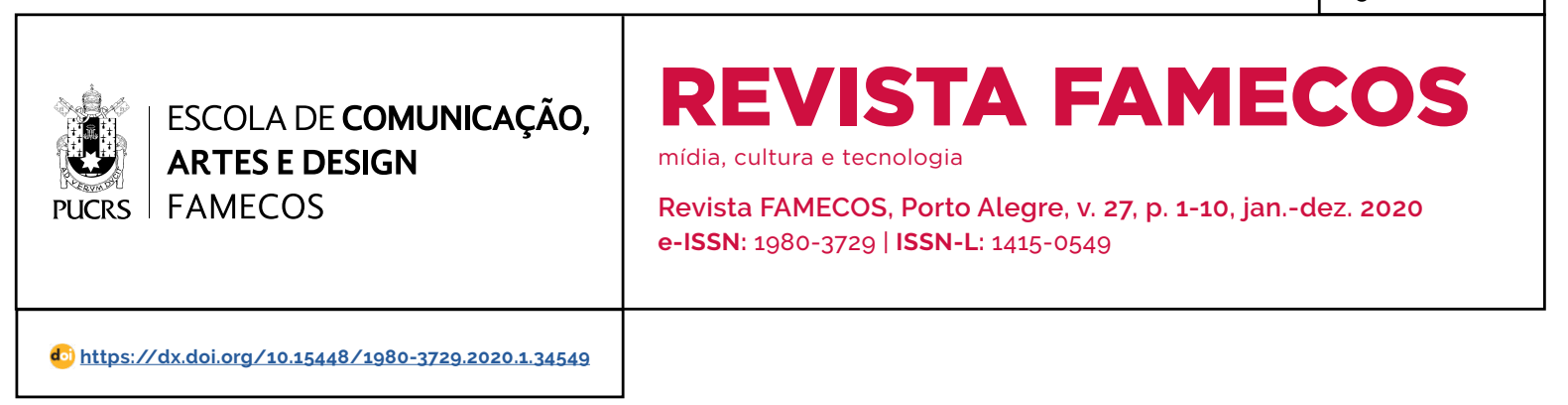

JORNALISMO

\title{
O telefone celular na rede-jornalismo: o conceito de equívoco e a invenção de uma teoria diferenciante
}

\author{
The cellphones on the journalism-network: the concept of equivocation and the \\ invention of a differentiating theory \\ El teléfono celular en la red-periodismo: el concepto de equivoco y la invención \\ de una teoria diferenciante
}

\section{Evandro José \\ Medeiros Laia ${ }^{1}$ \\ orcid.org/0000-0002-8463-3176 \\ medeiroslaia@yahoo.com.br}

Recebido em: 18 jun. 2019.

Aprovado em: 09 out. 2019.

Publicado em: 28 mai. 2020

\section{(c) (1)}

Artigo está licenciado sob forma de uma licença Creative Commons Atribuicão 4.0 Internacional.
Resumo: A partir da Teoria Ator Rede e do método da Cartografia de Controvérsias (LATOUR, 2005; LEMOS, 2013), fazemos um mapeamento das mudanças agenciadas pelo telefone celular na rede-jornalismo, a partir de vivências etnográficas, durante as manifestações contra a realização da Copa do Mundo, no Rio de Janeiro, em 2014, e durante os protestos do movimento Black Lives Matter, em Nova lorque. em 2015. A partir do material empírico, os conceitos de animismo e de tradução agenciam reflexões sobre o procedimento jornalístico, a partir da definição da notícia como uma tentativa de controlar o mundo ou, um tipo de controle coletivizante (WAGNER, 2010), que inventa o mundo a partir da redução da diferença. O contrário disso seria a invenção diferenciante, na qual a comunicação acontece pela diferença, em uma tradução-traição. Aventamos, então, a possibilidade de pensar um jornalismo em equívoco (VIVEIROS DE CASTRO, 2002, 2015), criando espaço para a proposta de uma teoria diferenciante do jornalismo.

Palavras-chave: Teoria do Jornalismo. Antropologia. Equivoco.

Abstract: From the Actor Network Theory and the Cartography of Controversies method (LATOUR, 2005; LEMOS, 2013), we map the changes promoted by the mobile phone in the journalism network, based on ethnographic experiences, during protests against the realization of the World Cup, in Rio de Janeiro, in 2014 and during the protests of the Black Lives Matter movement, in New York City, in 2015. From the empirical material, the concepts of animism and of translation organize reflections on the journalistic procedure, from the definition of news as an attempt to control the world, or a kind of collectivizing control (WAGNER, 2010), which invents the world from the reduction of difference. The opposite would be the differentiating invention, in which communication happens through difference, in a translation-betrayal. We then ventured the possibility of thinking a journalism in equivocation (VIVEIROS DE CASTRO, 2002; 2015), creating space for the proposal of a differentiating theory of journalism.

Keywords: Theory of Journalism. Antropology. Equivocation.

Resumen: A partir de la Teoría Ator Red y del método de la Cartografía de Controversias (LATOUR, 2005; LEMOS, 2013), hacemos un mapeo de los cambios agenciados por el teléfono celular en la red-periodismo, a partir de vivencias etnográficas, durante las protestas contra la realización de la Copa del Mundo, en Rio de Janeiro, en 2014 y durante las protestas del movimiento Black Lives Matter, en Nueva York, en 2015. Los conceptos de animismo y de traducción agencian reflexiones sobre el procedimiento periodistico, de la definición de la noticia como un control colectivizante (WAGNER, 2010), que inventa el mundo con la reducción de la diferencia. El contrario de eso sería la invención diferenciante, en la cual la comunicación ocurre por la diferencia, en una traducción-traición. Luego aventuramos la posibilidad de pensar un periodismo en equivocación (VIVEIROS DE CASTRO, 2002; 2015), creando un espacio para la propuesta de una teoria diferenciadora del periodismo.

Palabras-clave: Teoria del Periodismo. Antropologia. Equívoco. 


\section{A pesquisa}

Os encadeamentos que tornaram esta pesquisa possivel partiram do desejo de entender as transformações agenciadas pelo telefone celular nas rotinas jornalísticas. Por isso, estruturei o trabalho, inicialmente, a partir das redações de telejornal, seguindo pelo encontro com jornalistas fora do ambiente formal, em manifestações, na cidade do Rio de Janeiro, durante a realização da Copa do Mundo. $O$ encontro com midiativistas, freelancers e outros atores dessa rede foi consequência desta abertura para um mapeamento mais amplo. A metodologia de trabalho, orientada pela Teoria Ator-Rede (LATOUR, 1994, 2005: LEMOS, 2013) conta com as ferramentas básicas para uma incursão etnográfica: a observação participante, com anotações de campo, seguidas de entrevistas.

Usamos o termo invenção, aqui, no sentido proposto pelo antropólogo estadunidense Roy Wagner, como "um processo que ocorre de forma objetiva, por meio da observação e aprendizado, e não como uma espécie de livre fantasia" (WAGNER, 2010, p. 30). A busca por ferramentas para inventar uma pesquisa, a partir dos relatos e das informações colhidas em campo, me levaram a privilegiar alguns conceitos que se relacionam com a abordagem teórica escolhida e que acabaram por precipitar duas frentes de trabalho. A primeira delas é a tomada do conceito de animismo, na antropologia, e a sua atualização a partir de uma discussão que relaciona a capacidade de agenciamento, a partir de Gilles Deleuze e Felix Guattari (1992), com os objetos técnicos que povoam o nosso mundo contemporâneo, entre eles, o telefone celular. O estabelecimento de uma ontologia plana (LATOUR, 1994), na qual humanos e não humanos têm a mesma capacidade de afetar uma rede, aponta o caminho para a segunda frente de trabalho, o conceito de tradução, parte do esquema da Constituição Moderna, que inventa o mundo de maneira coletivizante e diferenciante (WAGNER, 2010), ao mesmo tempo. Bruno Latour (1994) lembrou que o problema, na Modernidade, é que esta operação nunca acontece sem que haja logo depois a purificação que separa de um lado humanos e do outro os não humanos. Esse esquema que retira a subjetividade dos objetos e a objetividade dos sujeitos acaba por reduzir os modos de existência possiveis.

A Copa do Mundo do Brasil, realizada entre os dias 12 de junho e 13 de julho de 2014, teve o Rio de Janeiro como uma das 12 sedes, onde foram disputados sete jogos, entre eles a grande final. Considerei, então, esse um ambiente produtivo para uma vivência etnográfica, com o objetivo de observar se e como as tecnologias móveis, com destaque para o telefone celular, altera o fluxo de produção do jornalismo na televisão, a partir da produção de imagens. Já as primeiras manifestações do movimento Black Lives Matter, em Nova lorque, foram registradas em dezembro de 2014. Acompanhei esses protestos, com o objetivo de mapear a rede em que estariam, a princípio, incluidos repórteres, pessoas que usam os smartphones para enviar imagens para as redações e, ainda, midiativistas, participantes ou não de coletivos. Essa tarefa, de acordo com a proposta de Bruno Latour, pressupõe um entendimento que considera entes além da formatação clássica das Ciências Sociais, superando a separação ontológica fundamental que coloca de um lado a natureza, misteriosa e acessivel somente aos iniciados, e do outro a cultura, construida e passivel de aprendizado por um processo de domesticação. A ActorNetwork Theory, ou ANT, como ficou conhecida nos Science and Technology Studies, é chamada pelo pesquisador brasileiro André Lemos (2013) de Teoria Ator-Rede, ou pelo acrônimo TAR, que também adoto aqui.

O conceito de rede sociotécnica, central na obra de Latour (1994), nasceu junto com a corrente dos Science Studies, com o objetivo de estudar situações, nas quais a ideia de natureza e de cultura, como zonas ontologicamente separadas, não funcionava quando aplicada ao objeto. Por isso, a pesquisa que apresento aqui não diz respeito às coisas em si, mas às relações entre elas. Roy Wagner (2010) desenhou uma dinâmica para explicar a maneira como, 
de acordo com o ele, o sentido das coisas se faz por contraste, o que o antropólogo chama de "cultura" só vai ficando visivel para ele aos poucos, à medida que chegam os problemas, as decepções e a saudade de casa. Isso faria o pesquisador entrar em conflito, em um tipo de choque que se expressa pela inadequação. A "cultura" local se manifesta então, por contraste, "a antropologia nos ensina a objetificar aquilo a que estamos nos ajustando como 'cultura', mais ou menos como o psicanalista ou o xamã exorcizam as ansiedades do paciente ao objetificar sua fonte" (WAGNER, 2010, p. 35). Essa objetificação seria um tipo de controle, exercido tanto pelo antropólogo com relação ao nativo, quanto desse em relação ao pesquisador, que também tenta entender o estranho que participa das atividades como se fosse integrante do grupo, mas de fato não é. Toda a ideia da sociedade como "invenção" do antropólogo, para Wagner, aplica-se a qualquer grupo: a diferença está na maneira como cada um destes coletivos tenta dar sentido ao mundo a partir do controle da natureza ou da cultura.

Ou seja: os nomes só fazem sentido no momento em que são pronunciados. Os conceitos são como pontes móveis, para usar o termo de Gilles Deleuze e Felix Guattari (1992). Vejamos a palavra "jornalismo", objeto da nossa reflexão, que tem sido tomada como a priori, um bloco homogêneo, uma essência, uma causa da qual parte consequências. Mas, se ao invés de uma essência, enxergarmos o jornalismo como uma rede, constituida por agenciamentos múltiplos, o conceito ganha fluidez e as mudanças tornam-se parte do movimento de controvérsias e posterior estabilização das redes sociotécnicas das quais participa e que forma. Tomando de empréstimo o conceito da TAR, vejo o jornalismo como uma caixa-preta, um tipo de cristalização, estabilização temporária de uma rede heterogênea de humanos e não humanos, que de tempos em tempos é reaberta, reorganizada e novamente fechada.
Após a resolução da controvérsia, tudo se estabiliza, passa para um fundo e desparece, até o momento em que novos problemas apareçam e a rede se torne mais uma vez visivel. Um aparelho de ar condicionado, por exemplo, é uma caixa-preta se está funcionando sem chamar a atenção. Parece uno, indivisivel, compacto. Quando quebra, vemos os diversos mediadores estabilizados que o compõe: peças, regras de garantia, disponibilidade de técnicos ou serviços especializados, problemas de engenharia ou de projeto etc. (LEMOS, 2013, p. 55).

As controvérsias mapeadas me ajudaram a abrir as caixas-pretas a partir do momento que a heterogeneidade da rede jornalismo ficou à mostra, com a entrada de novos elementos que desestabilizaram o fluxo de agências.

\section{As controvérsias ${ }^{2}$}

Na vivência etnográfica, durante a Copa do Mundo do Brasil, no Rio de Janeiro, o olhar para o fenômeno que pesquiso foi ampliado a partir da constatação de que existiam uma série de atores inesperados: midiativistas, black blocs, policiais, jornalistas, streamers, freelancers, colaboradores e outras denominações provisórias. Esses humanos, ao lado dos não humanos, como o telefone celular (mas também as câmeras, os carros de reportagem, os coletes de proteção), criaram associações bem mais complexas que a dicotomia que me levou inicialmente a campo. A experiência posterior, em Nova lorque, não foi diferente. Assim, pude verificar os agenciamentos provocados com a entrada do telefone celular em outro contexto. O mapeamento de campo, propriamente dito, foi organizado de acordo com temas abordados nas conversas e nas entrevistas, durante as vivências etnográficas.

O primeiro deles é a dinâmica de cobertura das manifestações, na cidade do Rio de Janeiro, durante a realização da Copa do Mundo de 2014. A observação mostrou uma dinâmica na qual repórteres de televisão e outros jornalistas de redação traçavam estratégias de atuação bem próximas ao que encontramos na cobertura diária

\footnotetext{
2 Este trabalho teve início em uma pesquisa realizada entre 2012 e 2016 . Os detalhes da descrição das vivências etnográficas realizadas dentro e fora das manifestações, e que fizeram emergir as controvérsias, foram suprimidas desta versão do relato, visto que o interesse aqui é apresentar a proposta da Teoria do Jornalismo em Equívoco, um desdobramento posterior da pesquisa.
} 
de notícias nos morros cariocas, em áreas de acesso restrito, ou mesmo negado a jornalistas, por conta dos riscos e de uma série de outras questões também mapeadas. Porém, "no asfalto", durante os atos, os jornalistas sentiam-se mais inseguros que na favela, justamente porque desconheciam os códigos de "sobrevivência", dominado pelos midiativistas. O telefone celular também apareceu como agenciador de contatos importantes, em uma rede construida pelo afeto, pelo contato pessoal do jornalista com a fonte, um tipo de relação cada vez mais mediado (na verdade, agenciado) por aplicativos para smartphones, como o WhatsApp, por meio dos quais jornalistas enviavam e recebiam mensagens, arquivos de áudio, textos, fotos e vídeos, em uma velocidade que alterou a lógica espaço-temporal da produção da notícia.

Muitas das estratégias de uso do telefone celular nas redes mapeadas tiveram inspiração no acoplamento pioneiro realizado por streamers, durante a Primavera Árabe, o movimento Occupy Wall Street e, posteriormente, por midiativistas, no Rio de Janeiro. O segundo tema abordado no mapeamento da rede mostra o trabalho das pessoas que transmitem manifestações e outros atos, usando o telefone celular conectado a uma estrutura gambiarra de produção, forjada na resistência. A experiência começou com a cobertura dos protestos de junho de 2013, no qual o trabalho do grupo funcionou como um tipo de vigilância, proteção para os manifestantes, contra a violência policial. As transmissões eram feitas, via de regra, com o uso de um aparelho de telefone celular, com uma conta pós-paga, com acesso à internet, além das baterias extras e do equipamento de proteção do midiativista, como o capacete.

Tanto no contexto das manifestações, quanto nas redações e nas incursões em campo, com os jornalistas, uma história precipitou-se como tema de conversas frequentes com os informantes: a morte do cinegrafista Santiago Andrade, da TV Bandeirantes, durante a cobertura de um ato, na Cinelândia, no centro do Rio de Janeiro, em fevereiro de 2014. Ele foi atingido por um rojão, disparado por dois manifestantes, de acordo com as investigações da polícia. O caso talvez seja a controvérsia mais ampla de todo este trabalho, pois instalou uma polarização que acabou conduzindo a criação de uma narrativa mítica em torno da figura do jornalista. A dicotomia jornalistas versus não jornalistas organizou-se em torno desse acontecimento, concentrando as atenções dos informantes e criando uma cortina de fumaça que encobriu outras questões. A história foi contada em detalhes, com a ajuda de informações de veículos de comunicação e entrevistas dos informantes.

A descrição de campo também abordou o período de observação do movimento Black Lives Matter, em Nova Iorque. Tudo começou em dezembro de 2014, quando o policial Daniel Pantaleo, do Departamento de Polícia de Nova lorque, foi inocentado pela morte do vendedor ambulante Eric Garner, depois de uma abordagem policial, enquanto vendia cigarros contrabandeados. Um vídeo mostra Pantaleo imobilizando Garner, enquanto ele grita: "I can't breathe", "Eu não consigo respirar", em tradução livre do inglês. A história causou comoção dentro e fora do País e deu origem a uma série de atos. Durante os protestos, em Manhattan, conversei e observei streamers e jornalistas, fazendo uma comparação com o que encontrei no Brasil, com relação ao uso do telefone celular e da tecnologia para transmissões ao vivo. Foi também nesse período que colhi o material que deu origem a mais um ponto da descrição de campo: durante uma nevasca, em março de 2015. um avião saiu da pista no aeroporto LaGuardia, o terceiro maior de Nova lorque. Acompanhei durante todo o dia a cobertura do caso, no local, observando como jornalistas das redes de televisão acessaram e se apropriaram de imagens feitas com smartphones, pelos passageiros do avião. 0 resultado é um mapa dos novos acessos possiveis a partir do agenciamento do telefone celular.

Por fim, o mapeamento mostrou como as redes de televisão estavam usando os smartphones e os donos destes aparelhos para aumentar a capacidade de cobertura, apropriandose do conteúdo gerado por usuário de uma maneira redutora, que parece trazer esse novo acoplamento para a mesma lógica do controle. O fato é que não há critérios definidos para esse 
tipo de uso, tanto no Brasil, quanto nos Estados Unidos. As empresas de comunicação cercam-se de consultores jurídicos, para evitar problemas posteriormente, e usam as imagens de acordo com as regras clássicas do jornalismo. Ou seja, o caminho acaba sendo o de tentar reduzir a diferença, um possivel outro modo de narrar, adequando os dados e os fatos a uma linguagem que cria generalidades, seguindo o que, na Teoria do Jornalismo, conhecemos como valores notícia (TRAQUINA, 2005). A partir disso considero então o jornalismo como um controle coletivizante, uma maneira de colocar ordem no mundo, a invenção de um cosmos no qual as diferenças sejam reduzidas às categorias pré-existentes.

\section{O equívoco}

A invenção de controvérsias, por mais que desestabilize a rede, é parte da dinâmica de criação, por isso é preciso olhar para elas como um espaço de construção de diferenças que aos poucos se tornam modelos, classificações, fechando-se novamente em caixas-pretas, mimetizando um bloco único de ação. O antropólogo Eduardo Viveiros de Castro (2004, 2015), ao observar comunidades indígenas da Amazônia, descreve um tipo de associação na qual a produção de diferenças é o motor da invenção, de maneira que a coletivização é evitada a qualquer custo, ao contrário do jornalismo, tradução de mundo que evita a diferença e busca marcadores coletivos. De acordo com Wagner (2010), há controle diferenciante e coletivizante em qualquer invenção. Sendo assim, de fato, o modelo que se desenha a partir da entrada do telefone celular na redejornalismo habita um outro universo diferente do mundo dos jornalistas de redação que participavam deste debate.

A provocação abre as portas para a aproximação com a arquitetura conceitual de Viveiros de Castro, com destaque para o método da equivocação controlada.
O perspectivismo projeta uma imagem da tradução como um processo de equivoco controlado - "controlado", no sentido de que o caminhar pode ser considerado um modo controlado de cair. O perspectivismo indigena é a teoria do equivoco, isto é, da alteridade referencial entre conceitos homonímicos. O equívoco aparece aqui como o modo de comunicação por excelência entre diferentes posições perspectivadas (VIVEIROS DE CASTRO, 2004 p. 5. tradução nossa). ${ }^{3}$

Viveiros de Castro propõe trazer as contribuições do pensamento ameríndio para a teoria antropológica, lembrando que a comparação é a base do trabalho de um etnógrafo, que faz paralelos entre a sua própria vivência e a observação de outras redes, para criar analogias, em uma tentativa de tradução. Supondo a separação clássica entre natureza e cultura, essa tradução permite que esse etnógrafo descubra caminhos diferentes para acessar uma mesma realidade. O problema é que, segundo Viveiros, quase nunca, em uma relação etnográfica, os dois entes desse processo comunicativo dividem a mesma posição, o mesmo ponto de vista, a mesma perspectiva, ou seja, a mesma realidade. O método da equivocação controlada comunica a diferença entre seres que habitam cosmos diversos, sem reduzi-las. É um deslocamento radical da epistemologia, ou seja, da forma de acesso ao mundo, como propõe o modelo multicultural, para a ontologia, a própria existência deste mundo que, na prática, se dá de maneira diferente para os dois lados da relação. Ele cita exemplos.

Penso no tipo de mito em que, por exemplo, o protagonista humano se perde no meio da floresta e chega a uma aldeia estranha. Lá os habitantes convidam-no a beber e se refrescar com uma cabaça de "cerveja de mandioca", que ele aceita com entusiasmo e, para sua surpresa horrorizada, o anfitrião colocou em na frente uma cabaça cheia de sangue humano (VIVEIROS DE CASTRO, 2004, p. 9, tradução nossa). ${ }^{4}$

3 Do original: Perspectivism projects an image as translation as a process of controlled equivocation - "controlled" in the sense that walking may be said to be a controlled way of falling. Indigenous perspectivism is the theory of equivocation, that is, of the referential alterity between homonymic concepts. Equivocation appears here as the mode of communication par excellence between different perspectival positions.

4 Do original: Here I have in mind the type of myth where, for example, the human protagonist becomes lost deep in the forest and arrives at a strange village. There the inhabitants invite him to drink and refreshing gourd of "manioc beer", which he accepts enthusiastically and, to his horrified surprise, his host place in front of him a gourd brimming with human blood. 
Esse tipo de história, comum na bibliografia de Viveiros de Castro, resume o Perspectivismo Amerindio: depois de ser capturado por outro ponto de vista, o humano passa a ver os animais como pares, como humanos também. É no momento de tomar a bebida que ele percebe o engano, o que o interlocutor chama de cerveja de mandioca, na verdade, para ele, é sangue humano: o mesmo nome, em realidades distintas, serve para designar coisas diferentes. Ai está o equívoco, fundamento da comunicação, na visão desse autor. Não é o entendimento, mas sim a incompreensão que marca o processo comunicativo, precipitando um tipo de comunicação pela diferença, uma invenção diferenciante.

A preocupação com uma única dicotomia, com a fixação de um inimigo, como observei nas vivências etnográficas, deixa escapar detalhes importantes das associações que agenciam o jornalismo: a Teoria Organizacional 5 já mostrou, há décadas, que as decisões dentro de uma redação vão muito além da vontade de um repórter, de um editor, às vezes até mesmo do dono do veículo. Situações de equivoco também apareceram no trabalho de campo quando ouvi informantes reproduzirem um pensamento cristalizado sobre o que seja jornalismo, para situar a ação deles como dentro e dos outros como fora do conceito. "Jornalismo é quando você mostra uma situação por todos os lados, ouvindo todas as partes. Todos os lados, por todas as partes" (LAIA, 2016, p. 151), afirmou, com segurança, uma apresentadora de telejornal, sem problematizar o acesso a "todos os lados". O trabalho dos coletivos, assim, não se enquadraria nesse conceito. Está aí a primeira controvérsia: havia (e ainda há) uma disputa em torno da palavra jornalismo. "Graças a Deus que há uma disputa!", disse um midiativista. "Porque o jornalismo, antes de ele se profissionalizar, ele era um jornalismo cidadão, fazia, tipo: 'Ah, eu sou advogado, mas eu me importo em fazer um jornal' Então, meio que volta a isso" (LAIA, 2016, p. 153), completou, me lembrando que essa disputa sempre existiu, já que a definição sobre o que é o jornalismo é temporária, precária, provisória, como qualquer conceito.

Neste caso, a redução é uma estratégia de enfrentamento da diferença. A questão sobre quem é e quem não é jornalista acaba funcionando com uma cortina de fumaça, o que importa é entender quem está fora e quem está dentro da definição, o controle coletivizante anula toda construção teórica que poderia apontar para um olhar além. Nas vivências etnográficas, ficou claro que os informantes não tinham uma visão panorâmica das associações que faziam, pelo contrário, particularmente para os que estavam inseridos na mídia mainstream. Ao mesmo tempo em que eles entendem que o celular é produtivo, a entrada deste não humano na rede gera uma insegurança em relação ao que está acontecendo em campo. Começam, então, as tentativas de reinvenção coletivizante, um reducionismo a partir da amplificação de polarizações menores, pontuais, que continuam mantendo a caixa-preta fechada. Portanto, é neste ponto que encontrei, uma segunda controvérsia significativa, só que essa mais ampla, de mais difícil mapeamento: havia um esforço para amplificar a polaridade jornalista versus não jornalista, na tentativa de manter fechada a caixa-preta, o que deixou de fora uma série de outras questões.

O mesmo aconteceu com relação às situações que envolviam qualquer tipo de violência e depredação, encaixada pelos jornalistas, durante esse periodo e até o momento da vivência etnográfica no Rio, na dualidade manifestantes pacíficos versus vândalos, ou black blocs. Na estratégia do enfrentamento está inscrita a possibilidade de reinvenção da controvérsia, reforçando belicosamente as dualidades que escondem o que de fato interessava saber.

Fazendo o objeto empírico falar, verifiquei que o telefone celular parece ter usado os jornalistas e os comuns sem distinção: para ele, não há diferença entre jornalista, midiativista, freelancer, outra pessoa qualquer, humana ou não. O contrário não é verdade: nem sempre

5 Nesta teoria, a notícia aparece como fruto dos interesses políticos e econômicos dos veículos. O jornalista acaba acomodando-se a esta perspectiva e internalizando os valores da organização, por uma série de motivos, entre eles, sua sobrevivência profissional. 
os jornalistas e os "comuns" usavam o telefone celular de maneira igual: há diferença entre os que o acessavam com mais e com menos legitimidade, pela perspectiva do jornalista. A partir do ponto de vista dos objetos, quem é e quem não é jornalista não é um problema, esse é um problema dos que se tornaram sujeitos, por meio do processo de purificação.

Um midiativista entrevistado me lembrou, nas entrelinhas de sua fala, que não é possivel tratar duas coisas diferentes a partir do mesmo conceito, a rede que agencia o jornalismo, essência, no caso deste estudo, as associações entre repórter, cinegrafista, câmera, microfone, carro, motorista, sistema de transmissão, editor, é bem diferente da rede que agencia o que ele apresenta.

Porque, afinal de contas, a gente não tá falando de uma van, de um link de transmissão, de uma concessão pública; a gente tá falando de um celular, com uma conta pós-paga, e a possibilidade de fazer essa transmissão ao vivo. Assim como as fotos em tempo real, eu faço o recorte, mas a transmissão, não porque ela é mais importante, mas porque é o meu, meu campo, né? Se isso é ou não é jornalismo, realmente a gente deixa a cargo de quem quer refletir mais sobre isso. A gente acredita que sim e seguimos independente do que as pessoas acham (LAIA, 2016, p. 199).

O tratamento do jornalismo de forma dessacralizada, por assim dizer, longe do fetiche, permite enxergá-lo como uma construção. Uma rede sociotécnica não tem como temporalidade a organização causa-consequência, já que é impossivel saber onde uma ação começa e onde ela termina, o que importa são as associações e o fluxo de agências. Portanto, ser jornalista não é um fim, mas um meio, passagem, condição agenciada pela perspectiva que se ocupa, ou seja, emergência da diferença que produz comunicação de um jeito fora da convencionalização, nem por isso (e por isso mesmo) mais ou menos legitima que outras formas. É preciso devolver ao jornalismo esta sua dimensão diferenciante de maneira legítima, para que isso possa ser feito sem contrabandos. A questão da diferença está no cerne desta proposta que chamo de jornalismo em equívoco, uma invenção de jornalismo na qual a diferença exista sem reduções.

Viveiros de Castro (2015) lembra da história do caçador de onça do conto "Meu tio, o llaruetê", de Guimarães Rosa, que termina se transformando em uma onça, capturado pela perspectiva animal. O onçador-onçado é um tipo de aliança intensiva, antinatural e cosmopolítica como a do xamã, que quando acessa a perspectiva de outros seres, não se transforma nesses seres, mas ativa, por meio de roupas, acessórios e rituais, um devir especíico desse outro possivel. Vestir a roupa de onça é menos esconder a condição humana e mais acessar um corpo outro e por consequência os poderes que os instrumentos deste outro corpo, desta outra rede sociotécnica, agenciam.

\begin{abstract}
As roupas animais que os xamãs utilizam para se deslocar pelo cosmos não são fantasias, mas instrumentos: elas se aparentam aos equipamentos de mergulho ou aos trajes espaciais, não às máscaras de carnaval. O que se pretende ao vestir um escafandro é poder funcionar como um peixe, respirando sob a água, e não se esconder sob uma forma estranha. Do mesmo modo, as roupas que, nos animais, recobrem uma 'essência' interna de tipo humano não são meros disfarces, mas seu equipamento distintivo, dotado das afecções e capacidades que definem cada animal (VIVEIROS DE CASTRO, 2015, p. 249).
\end{abstract}

Daí a ideia, precipitada nas vivências de campo, de que o jornalismo, mais do que uma essência, mais do que uma construção, é um ponto de vista: quem o habita é cooptado por aquela visão. Habitar o lugar do jornalismo é estar em uma rede sociotécnica na qual, além dos entes humanos, propriamente ditos, estão todos os outros elementos agenciadores. Por isso, importa menos o nome, o conceito cristalizado, e mais o caminho, as relações estabelecidas com os outros membros. É essa rede de relações, com o nome provisório de jornalismo, que traduz os acontecimentos do mundo. Essa tradução caminha para o mecanismo de purificação, negando seu elemento mítico, diferenciante, formando o que conhecemos hoje como jornalismo. Apostamos aqui em outra possibilidade: a da tradução que se assume como tal, sem caminhar para 
a purificação, apresentando-se como narrativa mítico-lógica e como rede incessante de invenção do mundo, como proposta diferenciante de um jornalismo em equívoco.

A figura do xamã aparece neste ponto da reflexão como um modelo, uma inspiração no sentido de promover um tipo de comunicação diferenciante, uma tradução que tem o papel de romper com o sentido padrão, ao mesmo tempo em que o reitera, em um processo que reconheço como o que Viveiros de Castro denomina de equivocação controlada.

O xamã ele próprio é um "relator" real, não um correlator formal: é preciso que ele passe de um ponto de vista a outro, que se transforme em animal para que possa transformar o animal em humano reciprocamente. O xamã utiliza - substancia e encarna, relaciona e relata - as diferenças de potencial inerentes às divergências de perspectiva que constituem o cosmos; seu poder, e os limites de seu poder, derivam dessas diferenças (VIVEIROS DE CASTRO, 2015, p. 173).

Nesde empreendimento, a tarefa não é encontrar um sinônimo na linguagem humana para representar um conceito de um animal, por exemplo, mas sim não perder nunca a noção da diferença dos homônimos entre a língua humana e as de outras espécies, já que não estamos falando do mesmo universo. O xamã faz o mundo funcionar, traduzindo mundos. No Perspectivismo Ameríndio, o que está por fora, a aparência que os não humanos ostentam, seria uma roupa, um invólucro, um acessório (assim como os cordões e como as penas, por exemplo), que esconde a humanidade deles, somente visivel para um igual ou para o xamã. que é o tradutor, aquele que acessa o outro mundo mas pode voltar, diferentemente dos "comuns" que, inadvertidamente, são capturados pela perspectiva animal e não voltam, "não têm malícia", "não são capazes de apurar informações com precisão", para fazer uma analogia com as frases que escutei de jornalistas de redação, em relação aos produtores de conteúdo vistos por eles como não jornalistas.

O xamanismo aparece então como um tipo de epistemologia relacional, diferentemente da epistemologia científica ocidental, é um jeito de agir que implica um modo de conhecer absolutamente oposto ao objetivismo ocidental. Se na epistemologia científica, conhecer é dessubjetivar, tirar a agência do sujeito que há nos objetos, no xamanismo amerindio é o contrário: conhecer é conferir agência, se relacionar, produzir em rede. Em contraposição a esta epistemologia científica, na qual conhecer é separar, analisar, apartar o que há de sujeito no objeto, o xamanismo produziria um conhecimento em processo, sem analogias fixadas, alterando a tradução de acordo com o contexto. Em uma extensão das comparações feitas por Viveiros de Castro, proponho, a partir desta perspectiva, pensar o jornalismo em equívoco como um análogo ocidental possivel para o xamanismo. Se o papel do jornalismo é traduzir os mundos possiveis para um mundo específico, o jornalista aparece então como este ser capaz de cruzar as fronteiras, conhecer e traduzir estas outras perspectivas, sem perder de vista o seu próprio mundo e as diferenças desse em relação aos outros.

Temos, de um lado, um jornalismo coletivizante, uma cristalização da rede cuja produção está pautada na redução das diferenças, e de outro, a proposta de um jornalismo diferenciante, uma produção em processo de (re)invenção constante, uma tradução que assume traição como parte inevitável do processo, abrindo mão da posição de maior legitimidade como processo de explicar os mundos, já que, antes de tudo, existem outros mundos possiveis, nos quais as mesmas palavras, os mesmos significantes, assumem significados diversos. O jornalismo em equivoco é um espaçotempo no qual a diferença pode existir sem reduções.

\section{A proposta}

Tomar o jornalismo como um a priori, uma essência pressuposta, é considerar uma hipótese como fato. Mas na Teoria Ator-Rede não há fato que não seja também feito. Por isso a ideia não é conceituar nem fato, nem feito, mas traçar o 
caminho entre um e outro, rastrear as associações para mapear os equívocos presentes nessa rede e desfazer caixas-pretas, apresentando outro jornalismo possivel, fruto das associações que se fazem agora. A questão fundamental desta pesquisa girava em torno de um equivoco, do uso da mesma palavra - jornalismo - para designar coisas diferentes, a saber, a invenção coletivizante e a invenção diferenciante na narrativa dos acontecimentos. $O$ que nos mostrou que $o$ jornalismo é também uma série de associações que tornam possivel um instantâneo do que conhecemos hoje como sendo essa atividade, um misto de representação dos "comuns" e de tradução do mundo.

Sendo o controle coletivizante, o objetivo dessa atividade é a purificação, que ganha com frequência os nomes de objetividade, transparência e isenção: esses são fetiches do jornalista, que acredita ser possivel alcançá-los, acredita neles como um peregrino que busca a iluminação, ou como o antropólogo usa a palavra cultura, de acordo com Roy Wagner. Assim, esse discurso da purificação tem se repetido à exaustão tanto nos bancos das faculdades, quanto na publicidade dos veículos de comunicação, que tentam inventar o jornalismo como um controle exclusivamente coletivizante. Isso não é possivel, já que nenhum tipo de controle é feito sem que haja um contexto que funcione como pano de fundo. Portanto, há também invenção diferenciante no jornalismo.

Por parte dos jornalistas, o conceito de valornotícia me serviu para pensar como essa invenção tem sido feita de maneira coletivizante. Mas o telefone celular, nesta pesquisa, agenciou outras ações, como a que foi precipitada com a chegada dos grupos de produção audiovisual e transmissão live streaming, um trabalho que pôde ser observado na Primavera Árabe, no movimento d'Os Indignados na Espanha e ainda no Occupy Wall Street, nos Estados Unidos. A vivência de campo no Rio de Janeiro trouxe a percepção sobre essa outra maneira de narrar o mundo, a partir dos protestos realizados em decorrência da Copa do Mundo no Brasil, que começaram um ano antes, em junho de 2013, na esteira dos fenômenos anteriores, fora do Brasil. Há diferenciação, mas também há coletivização nesse modo, como percebi. O episódio da morte do cinegrafista Santiago Ilidio Andrade e as polêmicas que se seguiram ao fato constituem a controvérsia na qual, a partir do discurso míticocoletivizante dos meios de comunicação e o seu reverso, é inventada uma narrativa diferenciante dos "comuns", agenciada por outras conexões.

Isso pode também ser chamado de jornalismo? Se mudam as associações, muda também o resultado final delas. Como o telefone celular e as novas associações em torno dele reinventam o mundo? Se isso será chamado de jornalismo ou não, é outra história. Se o caminho desse novo modo é mimetizar o jornalismo convencional, como aparece apontado em algumas das minhas observações, só o tempo vai mostrar. O que importa é saber que, partindo de agenciamentos diferentes, os resultados também são diferentes, nesse caso, os modos de habitar o mundo são diferentes. E que não há porque negar essas duas formas de narrar os acontecimentos e, assim, inventar o mundo. Uma saída que propus é a metáfora de um jornalismo, de um modo de narrar diferenciante, no qual a diferença exista. Esse trabalho é fundado em bases empíricas e apresenta uma contribuição possivel para a Teoria do Jornalismo. Mas essa não é uma proposta prática de jornalismo em equívoco, essa invenção, esse exercicio de imaginação é a etapa inicial de um trabalho mais amplo.

É a partir desse trabalho, então, que proponho a invenção de uma Teoria do Jornalismo em Equívoco, partindo de quatro pontos que emergiram das minhas observações: 1) o jornalismo é uma rede sociotécnica; 2) portanto, é preciso estar atento não só às atividades dentro das redações, mas a toda a rede de produção dos relatos, ampliando o escopo das pesquisas; 3) como rede sociotécnica, o jornalismo é o fluxo de agenciamentos e não as coisas em si, portanto, o conceito de jornalismo é temporário e muda; e 4) logo, a Teoria do Jornalismo em Equívoco se apresenta como uma abordagem relacional 
que inventa conceitos e decanta conclusões a partir do desenho das relações entre os entes, e não a partir das suas nomeações no ponto inicial da pesquisa.

A Virada Ontológica, movimento que começou na Antropologia e ganhou outros campos das Ciências Humanas, tem mostrado que é possivel usar outros modos de pensar, outros sistemas de existência, não ocidentais, para refletir o nosso próprio estar no mundo, o funcionamento do Ocidente. Essa aproximação com outro modo de existir, tão perigosa e produtiva, nos permite pensar o jornalista diferenciante como tradutor de mundos, aquele que acessa outros universos e volta para contar o que viu, criando analogias, metáforas, parábolas, traindo conceitos justamente porque a alteridade radical é inalcançável, faz sentido somente como diferença, sem redução. Na nossa metáfora de jornalismo, o jornalista é o mediador, aquele que transmite transformando o conteúdo e se transformando no outro que ele tenta traduzir. A Teoria do Jornalismo em Equivoco seria, então, uma teoria do jornalismo diferenciante, porque parte do exercicio de imaginação de um análogo do jornalismo coletivizante. A Teoria do Jornalismo em Equívoco reabilita a outra parte do jornalismo, que costuma não ser lembrada no discurso da criação dessa narrativa: a da invenção diferenciante do mundo.

\section{Referências}

DELEUZE, Gilles; GUATTARI, Felix. O que é filosofia? Rio de Janeiro: Editora 34, 1992.

LAIA, Evandro J. M. O jornalismo em equívoco: sobre o telefone celular e a invenção diferenciante. 2016. 219 f. Tese (Doutorado em Comunicação Social) Escola de Comunicação, Universidade do Rio de Janeiro, Rio de Janeiro, 2016. https://doi.org/10.20287/ ec.n26.v1.a07

LATOUR, Bruno. Jamais fomos modernos. Rio de Janeiro: Editora 34, 1994

LEMOS, André. A Comunicação das Coisas: teoria Ator-Rede e Cibercultura. São Paulo: Annablume, 2013.

TRAQUINA, Nelson. Teorias do Jornalismo: porque as notícias são como são. Florianópolis: Insular, 2005.
VIVEIROS DE CASTRO, Eduardo. Metafísicas canibais: elementos para uma antropologia pós-estrutural. São Paulo: Cosac e Naify, 2015 https://doi.org/10.22456/1984-1191.70016

VIVEIROS DE CASTRO, Eduardo. Perspectival Anthropology and the Method of Controlled Equivocation. Tipiti: Journal of the Society for the Anthropology of Lowland South America, v. 2, n. 1, p. 3-22, 2004. Disponivel em: https://digitalcommons.trinity.edu/ tipiti/vol2/iss1/1/. Acesso em: 20 mar. 2019.

WAGNER, Roy. A invenção da Cultura. São Paulo: Cosac e Naify, 2010.

\section{Evandro José Medeiros Laia}

Professor de Departamento de Jornalismo da Universidade Federal de Ouro Preto. Doutor em Comunicação e Cultura, pela Universidade Federal do Rio de Janeiro, com estágio doutoral no Departamento de Antropologia Aplicada do Teachers College Columbia University.

\section{Correspondência}

Universidade Federal de Ouro Preto, Instituto de Ciências Sociais Aplicadas

Ruas do Catete, 166

Centro

Mariana (MG) - Brasil 